This item was submitted to Loughborough's Research Repository by the author.

Items in Figshare are protected by copyright, with all rights reserved, unless otherwise indicated.

\title{
Materials analysis of stereolithography resins for use in rapid manufacturing
}

PLEASE CITE THE PUBLISHED VERSION

PUBLISHER

(C) Springer Verlag

VERSION

VoR (Version of Record)

LICENCE

CC BY-NC-ND 4.0

\section{REPOSITORY RECORD}

Hague, Richard J.M., S. Mansour, Naguib Saleh, and Russell A. Harris. 2019. "Materials Analysis of Stereolithography Resins for Use in Rapid Manufacturing". figshare. https://hdl.handle.net/2134/4643. 
This item was submitted to Loughborough's Institutional Repository (https://dspace.lboro.ac.uk/) by the author and is made available under the following Creative Commons Licence conditions.

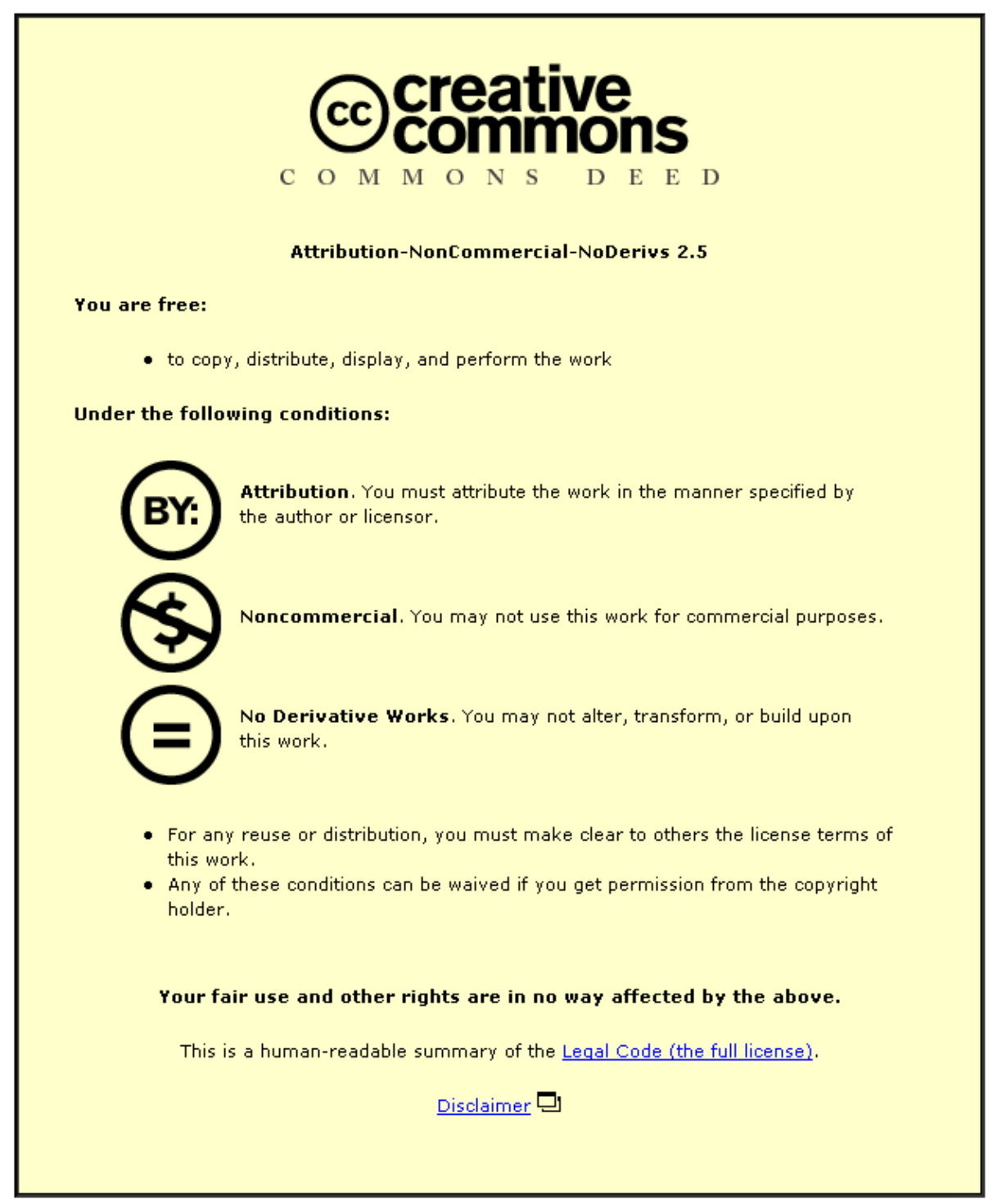

For the full text of this licence, please go to: http://creativecommons.org/licenses/by-nc-nd/2.5/ 
Materials analysis of stereolithography resins for use in Rapid Manufacturing

R. HAGUE, S. MANSOUR, N. SALEH, R. HARRIS

Rapid Manufacturing Research Group, Wolfson School of Mechanical and Manufacturing

Engineering, Loughborough, UK

The use of Rapid Prototyping (RP) techniques for the production of end-use parts is increasing to a stage where Rapid Manufacturing is being undertaken. This paper documents significant initial investigations into the properties of Accura SI40 and SL7560 resins which represent two state of the art stereolithography resins that are aimed at end-use part manufacture. This information has previously been unavailable and is vital for their consideration in end-use part manufacture. The impact of various levels of post curing (ultraviolet and thermal) on the tensile, flexural and impact properties are investigated and correlated with differential scanning calorimetry (DSC) analysis. The isotropy/anisotropy nature of the two materials and also the effect of the notch creation method on the impact resistance were also studied.

\section{Introduction}

There are three generic methodologies for the production of prototypes or manufactured parts that include [1]: 1. Subtractive: Processes that remove material from a bulk material such as milling, turning, electrodischarge machining (EDM), etc.

2. Formative: The use of a tool to produce a part in processes such as injection moulding, die casting, forging, etc. (NB: it should be noted that usually the tool is produced by subtractive methods.)

3. Additive: This is a relatively new approach to the manufacture of prototypes or end-use parts and is generally referred to as either Rapid Prototyping (RP) or increasingly Rapid Manufacturing (RM). This additive manufacturing principle and one process in particular (stereolithography) is the subject of this paper. Rapid Prototyping (RP) is the collective name for a set of different technologies and processes used to manufacture models directly from a three-dimensional (3D) Computer Aided Design (CAD) model by constructively building them in layers. The RP processes include, amongst others, Stereolithography (SL), Laser Sintering (LS), Fused Deposition Modelling (FDM) and 3-Dimensional Printing (3DP). Other associated names include Solid Freeform Fabrication (SFF) and Layered Manufacturing (LM). RP technologies have gained diversity, complexity, sophistication and popularity since their introduction in the late 1980's. The use of RP in product design and development has had 
a significantly positive effect and has been shown to reduce development costs by 40 to $70 \%$ and the time to market by as much as 90\% [2]. RP parts have been used in a range of areas such as design visualisation, pattern building, assembly verification and functional testing. However, it is not the aim of this paper to describe the various RP processes, as they are well documented elsewhere [3-5].

The concept of Rapid Manufacturing (RM) - the production of end-use parts from additive manufacturing systems-is evolving from RP. The principal advantage of the additive manufacturing processes (including most, but not all, of the currently available RP techniques) is the ability to manufacture parts of virtually any complexity of geometry entirely without the need for tooling. If this principle were extended to true manufacturing processes then the opportunities for product design and manufacturing are immense.

Though some well-documented 'Rapid Manufacturing' is being undertaken today, these examples are being undertaken with existing RP systems [6, 7]. However, no current RP technology can be truly considered as a manufacturing process as there are several limitations that impede their use as manufacturing systems. The most important areas of concern include:

1. The machines are designed for prototyping and not for manufacturing which means that they are working at slow speed, relatively low accuracy and produce parts with poor surface finish [8].

2. Current high cost of machines (up to $£ 750 \mathrm{~K}$ ) and materials (£160/kg for SL resins) [8].

3. The limited number of materials (around $46 \mathrm{SL} \&$ 15 LS materials in USA \& Europe) [6]. This is small compared to other manufacturing techniques such as injection moulding that has thousands of available materials.

4. The very limited information about the mechanical properties of the materials at different temperatures, humidity and ages, which is one of the main reasons that designers do not have any confidence in specifying RP materials for producing end-use parts.

Therefore, there is much work to be undertaken to convert the principles of additive manufacturing into viable manufacturing techniques that can be exploited more universally. However, it is anticipated that true RM manufacturing systems will become available within a 5 to 10 year period and their introduction will truly amount to a new industrial revolution [9]. One such research project that is looking into the possibilities for RM is the "Design for Rapid Manufacture" project at Loughborough University [10]. The project is funded 
by Engineering Physical Sciences Research Council (EPSRC) as part of Loughborough's Innovative Manufacturing Research Centre (IMRC). The project industrial partners include: 3D Systems, Custom Design Technologies Ltd., Delphi Diesel Systems, Jaguar and Land Rover Research, MGRover Group and Huntsman (formerly Vantico).

In addition to the design aspects [11], one of the main areas of the Design for Rapid Manufacture project concerns the characterisation and analysis of the mechanical properties of two materials manufactured using a stereolithography RP machine. The materials tested were SL 7560 by Huntsman [12] and SI40 by 3D Systems [13] - both materials represent the state of the art in SL materials and are aimed more for manufacturing purposes as it is considered that their mechanical properties are approaching those of traditional engineering plastics which will allow them to be used in more demanding end-use applications.

\subsection{Scope of the investigations}

As RP machines have historically rarely been used to produce fully functioning end-use parts, there has not been an overriding need or demand to know their full material properties. However, as mentioned previously, increasingly RP parts are being used in end-use part manufacture (RM) and therefore it is vital that designers are made aware of the various mechanical properties of the materials produced on the RP systems to give them more confidence in specifying the materials in their designs. Limited information is available but there are large gaps in the data set.

For automotive applications, designers typically need material properties ranging from $-40 \circ \mathrm{C}$ to +140 . C. Therefore, the research project is undertaking an extensive material's testing program for the two SL materials over this temperature range, at three different humidity's (dry, $50 \%$ relative humidity $(\mathrm{RH})$ and totally immersed in water) and also over extended time periods (1, 4, 13, 26 and 52 weeks) to consider ageing of materials. This represents the most significant data generation for materials being used in RP and RM to date, with each material requiring around 5500 individual tests. In order to conduct the proposed investigations, initial tests were conducted which yielded some interesting aspects of these two resins. It is these initial investigations that are detailed in the paper. The on-going ageing results will be published in due course.

\subsection{Objectives}


The objectives of this paper are to:

1. Investigate the isotropy/anisotropy of SL7560 \&

Accura SI40.

2. Investigate the effects of different methods of post-curing on the mechanical properties of Accura

$\mathrm{SI} 40$ and relate these properties with the level of polymerisation

within the test samples using differential

scanning calorimetry (DSC).

3. Compare the impact strength of mechanically notched test specimens with those that have the notch

built on the SL machine for SL7560 and Accura SI40 resins.

\section{Methodology}

In order to conduct the investigations and achieve the objectives of the project the following equipment and experimental approaches were adopted:

\subsection{Stereolithography apparatus}

Despite the fact that true "RM" does not exist, there has been a significant increase in the use of RP technologies for end-use part manufacture which has mainly been afforded by the marked development of the processes and materials during the past 15 years. Of the available RP processes, the stereolithography (SL) process has always been one of the most significant RP technologies and it is one of the technologies that is considered to be suitable as a future manufacturing process [11]. It is this process and the mechanical properties of the materials that are produced by it (specifically SL7560 and Accura SI40) that are the subject of this paper.

The SL technique is based on the process of photopolymerisation, in which a liquid resin is converted to a solid polymer on exposure to computer controlled ultraviolet laser radiation [14]. The photopolymer is selectively cured on a layer by layer (additive) basis where the cured area corresponds to the desired cross-section of the required shaped article to be formed, which is in turn taken from the 3D CAD model of the part being produced. The solidified layer is then lowered by the amount of the required layer thickness and a recoating blade moves over the surface to apply a new layer of resin. The process is repeated until a green model of the required shape is finished. It should be noted that support structures are used to anchor the part to the build platform during the build process and to enable the production of over-hanging features. On completion of the build, the model is usually post-cured under high intensity ultraviolet radiation to complete the curing process [2]. Thermal post curing is often, 
but not always employed to stabilise and increase the mechanical properties of the produced part, though the decision of whether to thermally post cure is dependent on the particular SL material being used. For example, the Accura SI40 resin tested benefits greatly by the use of a thermal post curing stage whilst the effect on the SL7560 is far less pronounced and its use is therefore debateable. The use of a thermal post curing stage is in effect an accelerated ageing mechanism and can also have deleterious effects if not controlled correctly.

\subsection{Test specimens manufacture and preparation}

The equipment used to build the test samples was a SLA7000 by3DSystems. The build volume for this machine is approximately $500 \mathrm{~mm} \times 500 \mathrm{~mm} \times 600 \mathrm{~mm}$ (XYZ). Various parameters can be adjusted to optimise and customise the process for a specific task, with the most significant of these being "over-cure," "hatch-cure," layer thickness and the recoating parameters [14]. The definition and impact of each of these parameters are given elsewhere [2]. However, it should be noted that for each resin the build parameters were provided and recommended by the resin suppliers and were used consistently for the test specimen's manufacture. The build styles used were based on the ACES (Accurate Clear Epoxy Solid) format which was designed specifically for use with epoxy resins.

All the samples for each set of tests were produced during the same build and then cleaned and post cured at the same time. They were kept in a dark place to prevent further post process ultraviolet curing and in a controlled environment $(50 \% \mathrm{RH} \& 20 \circ \mathrm{C})$ prior to testing. For tests investigating the impact of post curing on the materials properties, 13 samples were produced for each series of tests and three of them were randomly selected for DSC analysis with the remainder being used for mechanical testing.

The build orientation and its affect on the isotropy of the material is one of the aspects considered in this paper and is covered in Section 3.1. However, it should also be noted that the build orientation also has a profound affect on the surface finish of the completed part due to the layer-wise manufacturing process employed [15], though this aspect is not considered in this paper as it has no bearing on the tests undertaken.

\subsection{Test procedure and standards}

The mechanical properties investigated in this work included: Tensile (Young's modulus, ultimate tensile 
strength and \% elongation at break), Flexural (flexural modulus and strength) and impact strength (using Izod tests). The tests were strictly conducted according to ISO standards [16-18] and all the test specimens were produced from 3DCADmodels to the dimensions specified in the relevant standard.

All the tests were conducted in a temperature and humidity controlled room. The tensile and flexural tests were performed on a Zwick 1030 [19] tensile test machine with a nitrogen facility for low temperature tests combined with a Zwick heated cabinet for the higher temperature tests. A Zwick 5102 pendulum impact tester, configured for Izod tests was used for impact analysis.

\subsection{Differential scanning calorimetry (DSC)}

For this work it was required to establish and quantify the degree of polymerisation of the SL materials.

To achieve this differential scanning calorimetry (DSC) analysis was conducted. DSC is a thermal analysis technique used to directly measure the temperature and heat flow to a sample during heating in a controlled atmosphere over a period of time. This technique provides quantitative information about physical changes by monitoring endothermic and exothermic processes that represent material transitions. Specific information that can be obtained include: glass transition, melting point, crystallisation, phase change; etc., but most importantly with respect to this work is the amount of heat expelled as a relation to the further curing experienced during the DSC analysis.

The DSC apparatus consists of an enclosed cell containing two aluminium vessels which are connected to thermocouples. Contained in one vessel (pan) is the sample to be examined and the comparison pan is kept empty.

Inside the DSC cell, the sample pan and the reference pan sit on a raised platform on the cell's heater.

As heat is transferred, the differential heat flow to the sample and comparison sample is monitored by area thermocouples. The heat input and temperature rise for the material under test is compared to those for the comparison pan while both are subjected to constant linear temperature increase. The results from these measurements allow the heat flow to be plotted as a function of temperature that can indicate the periods of thermal transition of the sample material [20]. The apparatus used was a modulated DSC machine by TA Instruments, model 2920 [21]. The cell atmosphere was provided by refrigerated nitrogen cooling 
system produced by TA instruments. The temperature range of the DSC analysis used was 10 to $170{ }^{\circ} \mathrm{C}$ with a heating rate of $10 \circ \mathrm{C} / \mathrm{min}$. The recommended weight for each DSC analysis sample was 5-20 mg [20].

3. Experimental method, results \& discussion For ease of reporting, the experimental method and results for the various experiments conducted are given with a corresponding discussion of the results contained in the same section. This is followed by conclusions of the results that are given in Section 4.

\subsection{Isotropy/anisotropy validation}

Due to the additive layer-wise nature of the SL build process, there is some debate as to whether the produced materials are isotropic or anisotropic. Therefore, before proceeding to the full range of ageing tests where a significant amount of test coupons are to be built, it was important to ascertain and confirm previous work into the isotropy (or otherwise) of the material with the aim of consolidating the number of subsequent tests. Isotropy, or rather anisotropy, can also have a particular influence on how a part is designed and thus it's determination is of importance.

The investigations included tensile, flexural and impact tests that were conducted at a temperature of $20^{\circ} \mathrm{C}$. The samples were produced in three different orientations (Flat, Upright and Edge) as depicted in Fig. 1 (for the tensile samples). 


\section{Z Axis}

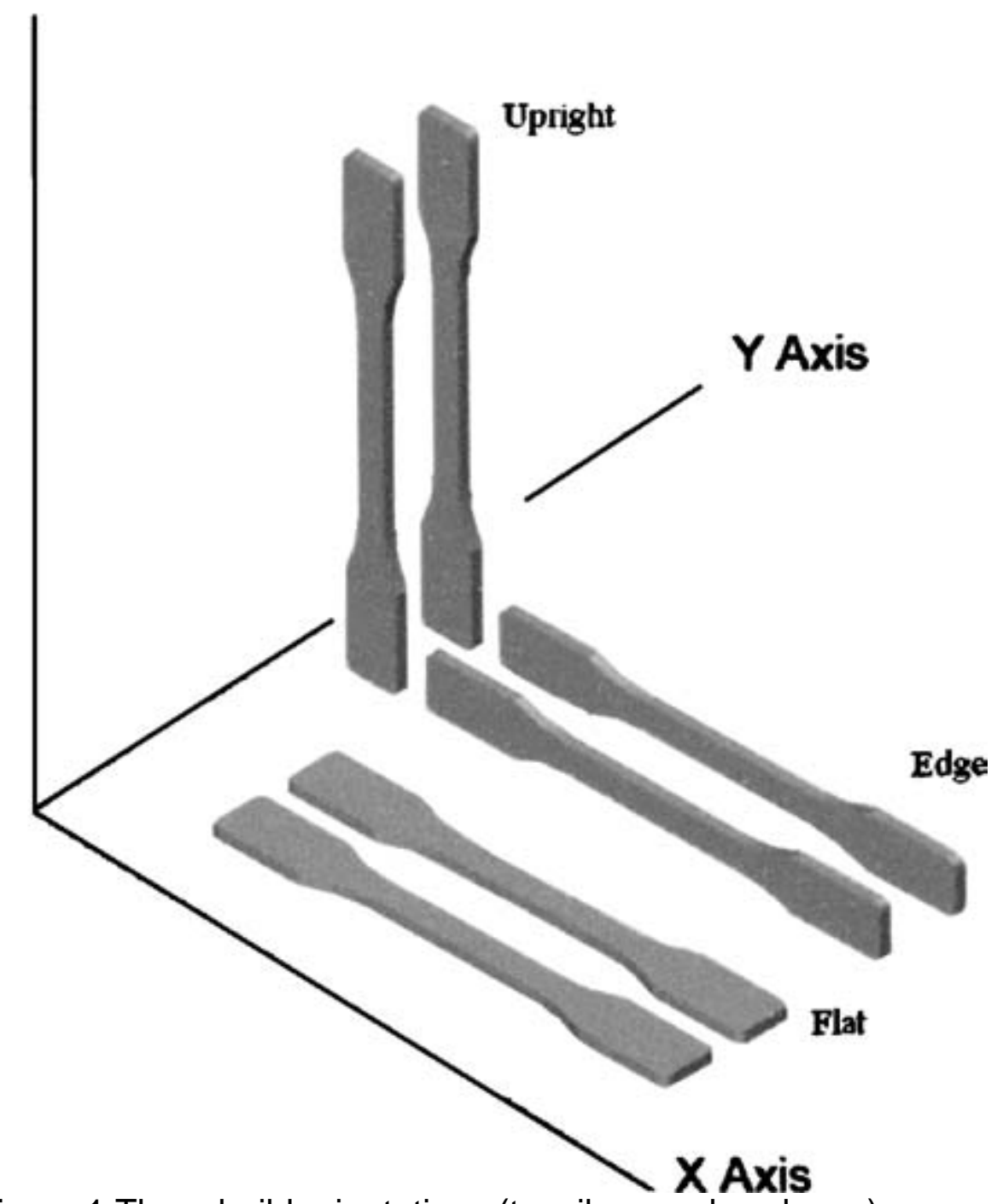

Figure 1 Three build orientations (tensile samples shown).

Similar build orientations were used for the impact and flexural test samples. The tests were conducted according to ISO standards and Table I shows the average values (for 10 samples) of the conducted tests for SL7560.

It can be seen from the results in Table I that the maximum variation in mechanical properties of SL7560 resin is less than $5 \%$. Similar results were found for the Accura SI40 resin. Therefore, it can be concluded that the stereolithography process produces broadly isotropic parts and that the build orientation has little effect on the mechanical properties of parts. These results are fully consistent with previous published works $[2,22]$.

Therefore, from this work it can be concluded that for the SL process, the build orientation can be optimised for either the reduction of build time, limitation of support structures or improvement of surface finish 
(to reduce the stair-step effect) without any consideration for influencing the mechanical properties.

Mechanical properties

Max. tensile strength (Mpa)

Young's modulus (GPa)

Flexural strength (MPa)

Flexural modulus (GPa)

Impact strength $(\mathrm{kJ} / \mathrm{m} 2)$
Build orientation

Flat Edge Upright Max. \% variation

54.956 .453 .7

4.8

2.62 .72 .7

3.7

$92.596 .395 .3 \quad 3.9$

$2.12 .22 .1 \quad 4.5$

$2.52 .42 .4 \quad 4.0$

TABLE I Isotropy/anisotropy test results for SL 7560

\subsection{The impact of post-curing methods on}

materials properties

As mentioned previously, the "green" part that has been produced on the SL machine needs to undergo subsequent post curing operations to polymerise the materials to an extent that they can be safely handled. This is usually achieved by exposure of the green part in a UV chamber for a period of approximately $1 \mathrm{~h}$. In addition, much work has been undertaken that shows that a thermal post cure cycle can improve the mechanical properties for some SL materials [23-27]. During a thermal post cure cycle the resin is further cured by thermal means and therefore it also becomes more brittle; this consequently reduces the impact strength and the $\%$ elongation at break. For a given geometry of part, as the material cures, a flexible part will therefore be converted to a stiffer part which will result in an increased Young's modulus. Also, the extra cross-linking which takes place will improve the ultimate tensile strength of the material whilst at the same time, the flexural strength and flexural modulus will also increase [28, 29].

For the purposes of this study, the effects of thermal post curing on some of the mechanical properties of Accura SI40 have been investigated.To achieve this, the following three methods of post curing were applied:

1. Normal post curing (NPC): 90 Min in UV post curing apparatus

2. Thermal post curing 1 (TPC1): $\mathrm{NPC}+2 \mathrm{~h}$ at $80{ }^{\circ} \mathrm{C}$ (Some prototypes or parts will undergo this cycle for improved properties, depending on the particular resin used)

3. Thermal post curing 2 (TPC2): NPC+24 h at 80 。 (NB. This curing cycle is excessive and no prototypes or parts would normally undergo this level of post curing as it will result in highly brittle parts. However, exposing the material to this level of cure is similar to an extreme accelerated ageing of the samples and 
thus the results are indicative of how further curing will influence the materials properties and are important if the parts are for end-use).

\subsubsection{Mechanical tests}

The upright build orientation was selected for the tensile and flexural test samples, whilst the impact test samples were produced in a flat orientation. The results for tensile, flexural and impact properties are given in Table II. These results confirm that as the above thermal post curing cycles are executed, the samples become more brittle and the impact strength and \% elongation at break reduce whilst Young's modulus, maximum tensile strength, flexural modulus and strength have increased. These results are in accordance with those obtained by other researchers [30].

\subsubsection{Confirmation by DSC analysis}

To validate the mechanical test results, DSC analysis was conducted where the degree of cure due to the post curing history were quantified. Fig. 2 shows a typical example.

(Young's modulus MPa) (Max. tensile strength MPa) (\% Elongation at break) (Flexural modulus) (Flexural strength MPa) (Impact strength $\mathrm{kJ} / \mathrm{m} 2$ ) NPC (2337.55) (52.65) (7.62) (1842.73) (88.04) (4.68) TPC1 (3038.95) (80.49) (7.06) (1993.9) (112.9) (3.05) TPC2 (3072.39) (84.12) (6.75) (2002.79) (114.89) (2.53) TABLE II Changes in mechanical properties of Accura SI40 due to three levels of post curing 


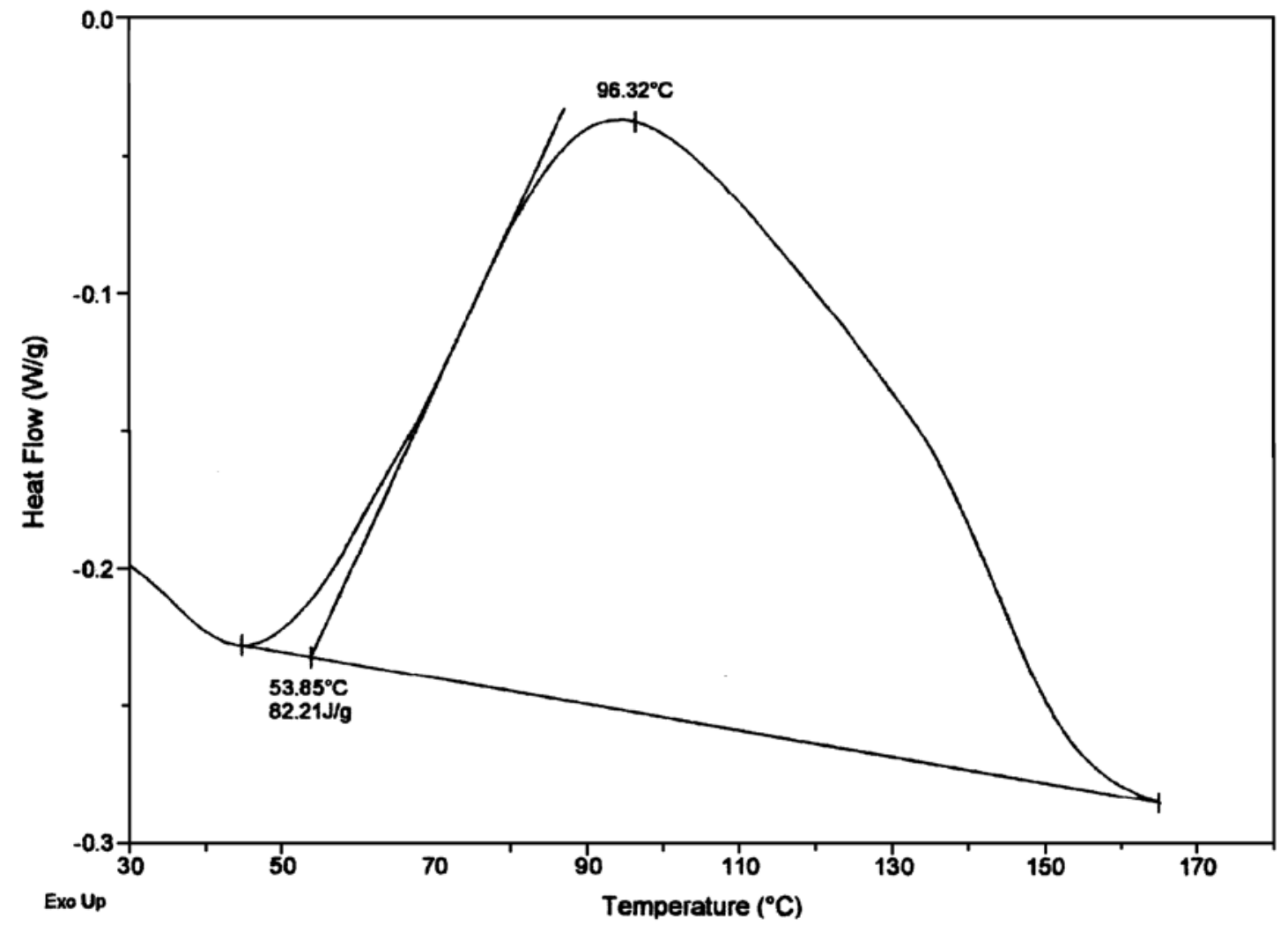

Figure 2 DSC results for Accura SI40 (post curing cycle: NPC).

DSC plot that was obtained for the SI40 in its Normal Post Cure (NPC) state. The peak in the plot represents an exothermic reaction due to the curing of the resin during its slow heating in DSC process. The area under the curve can be related to the amount of cure by comparison that has taken place to fully cure the sample.

This result shows that there is still a significant amount of curing that can be achieved in samples that have only undergone UV post curing. 


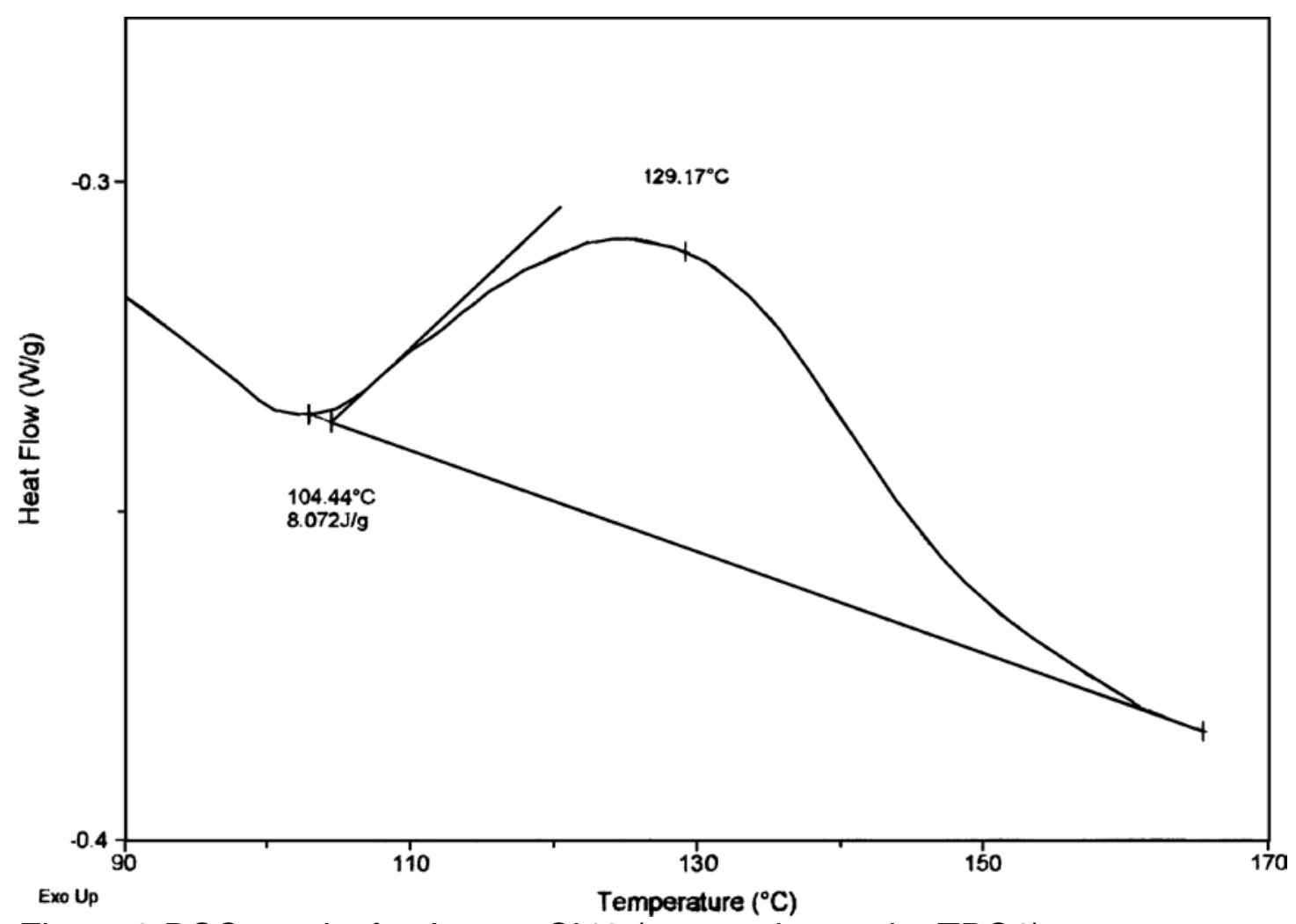

Figure 3 DSC results for Accura SI40 (post curing cycle: TPC1).

Figs 3 and 4 detail the DSC plots for the thermally post cured samples (TPC 1 \& TPC 2) which show that there is a progressive reduction in the amount of cure after a thermal post cure stage. The amount of dissipated heat from the samples in their different states of post cure (that is inversely proportional to the level of cure of the samples) is detailed in Table III. These results are calculated from the area under the DSC curves and are averaged for three samples per post curing state. 


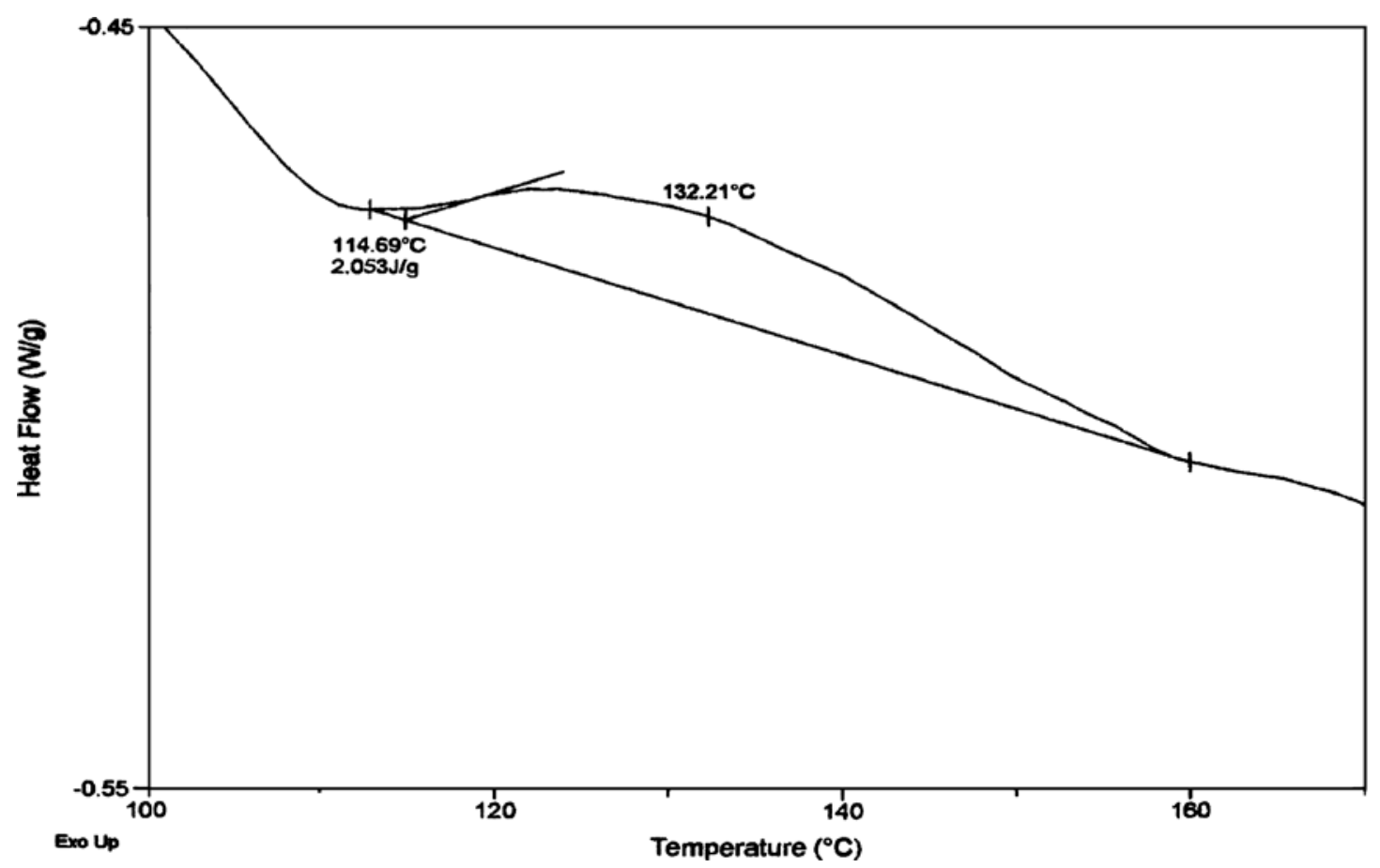

Figure 4 DSC results for Accura SI40 (post curing cycle: TPC2).

Figs 2-4 and Table III validate the results of the mechanical tests (Table II). As the level of cure of the samples tested increases (from NPC through to TPC2), the heat dissipated by the samples is shown to decreaseconfirming and increase in initial cure-which further correlates to a matching change in the mechanical properties of the materials.

3.3. Effect of notch manufacture method on impact strength In conventional impact testing, the required notches are usually mechanically introduced into the test samples-indeed, this is specified in the relevant ISO Standard [18]. However, with RP/RM processes it is entirely possible to include the notch into the CAD file and manufacture this design detail as the part is being built. Notches were introduced into a group of ten Accura SI40 impact samples using a mechanical method (Izod notching was used). These samples were tested and compared with another group that were produced with notch being introduced using the SL machine. 


\begin{abstract}
Dissipated heat $(\mathrm{J} / \mathrm{g})$
UV only 2 hTPC $24 \mathrm{hTPC}$

Sample $1 \quad 86.7708 .0720 .915$

Sample $2 \quad 77.30013 .6301 .351$

Sample $3 \quad 82.21010 .5602 .053$

Average 82.09310 .7541 .440

TABLE III Average heat dissipated during curing for three post curing cycles
\end{abstract}

Similar investigations were carried out for SL7560. In order to minimise the staircase effect of the build process on the notch profile, all the samples under investigation were built in the flat orientation, as shown in Fig. 1 (for tensile test samples). The averaged impact strength for all groups of samples being produced is shown in Table IV. Fig. 5a and b show scanning electron microscope (SEM) pictures of mechanically and SL-notched samples for Accura SI40 resin, respectively.

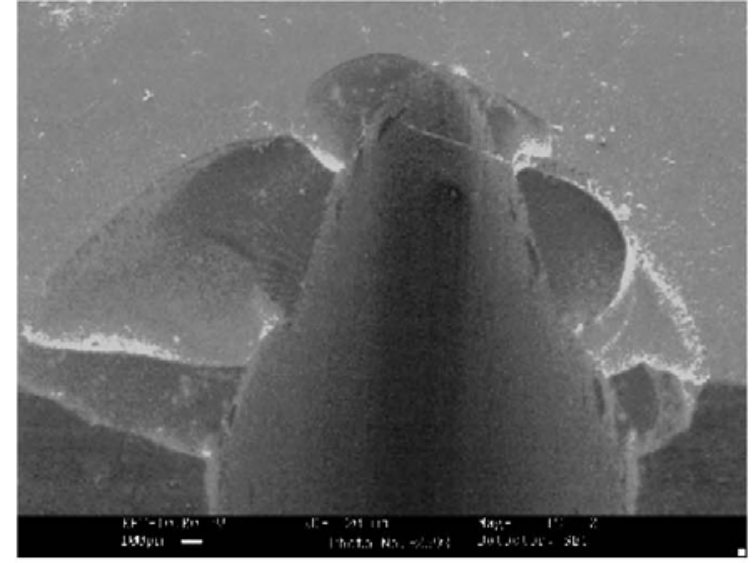

(a)

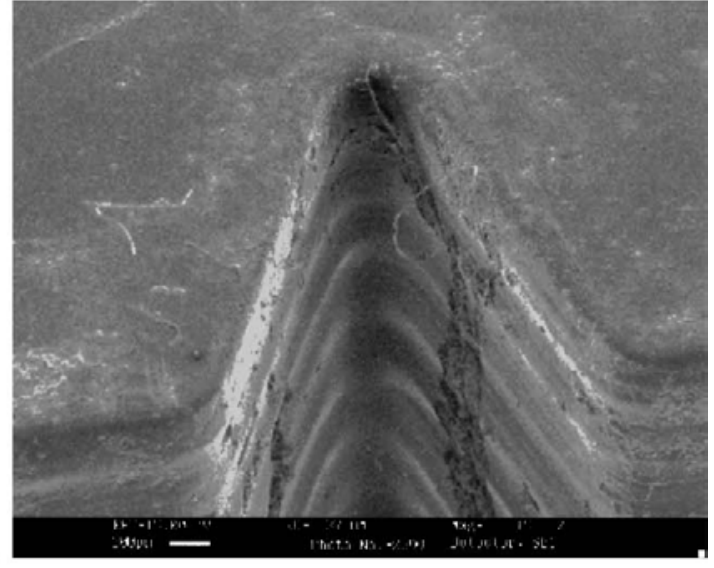

(b)

Figure 5 SEM presentation of Accura SI40 resin after sputter coating (tilt angle $\left.=45^{\circ}\right)(a)$ Mechanically manufactured notch and (b)SLA manufactured notch.

From Table I, it can be observed that the impact resistance of the SL-notched samples has improved considerably in comparison with the mechanically notched samples for both the SL7560 and SI40 materials. Fig. 5b, shows the border curing, which has resulted from the notch profile being manufactured on a Stereolithography machine and it is this border curing that has had the profound affect on the impact strength. This effect clearly does not exist on the mechanically manufactured notch as shown in Fig. 5 a which has also shown to be damaged during the notching phase. This increase in the impact strength has potentially a great impact on the design of features such as self tapping screw threads, gear teeth, etc. If the screw thread were actually designed into the CAD model and 
then produced via the RM process, then this would afford a much greater resistance to failure than if the self tapping screw was directly screwed into the produced part.

Impact strength $\mathrm{kJ} / \mathrm{m} 2$ (Material Mechanically manufactured) (Build process manufactured) (\% Improvement)

SL7560 (2.4) (5.7) (138)

Acura SI40 (2.5) (4.2) (68)

TABLE IV RP vs. machine manufactured notch

\section{Conclusions}

This paper has detailed significant initial results from an ongoing research project that is investigating the material properties of two state of the art stereolithography materials that are aimed for end-use part manufacture. The isotropy, effects of thermal post curing and impact test notch introduction methods have been presented.

Investigations into the isotropy/anisotropy behaviour of SL7560 and Accura SI40 concluded that the parts produced are broadly isotropic and that the build orientation does not affect their mechanical properties.

This work confirms previous work and has important implications for the design of parts produced via stereolithography. Three different post-curing cycles were selected and the tensile, flexural and impact properties of Accura SI40 were investigated. It was shown that by exposing the Accura SI 40 material to a thermal post curing cycle further polymerises the resin. Consequently, Accura SI40's Young's modulus, ultimate tensile stress, flexural modulus and strength improved while its impact strength and \% elongation at break reduced. DSC analysis correlated the results obtained from the mechanical tests. This indicates that the mechanical properties can be adjusted according to the post-curing methodology used which may be desirable in the design of the end use part.

The method of creating the notch in impact samples was found to greatly influence the results of the tests. Creating the notch within the 3D CAD file and producing this directly on the SL machine significantly improves the impact resistance with respect to mechanically notched samples. This result reveals that if design features such as screw threads or gear teeth are included at the 3DCADdesign stage and subsequently manufactured by $\mathrm{SL}$, then this will increase their resistance to damage due to the increased impact strength afforded to the parts. 
Acknowledgements

UK Engineering \& Physical Science Research Council

(EPSRC) and the project partners that include: 3D Systems,

Custom Design Technologies Ltd., Delphi Automotive

Systems, Jaguar \& Land Rover Research, MG

Rover Group and Huntsman (Vantico).

References

1. S . O. ONUH and K. B. HON, Int. J. Tool Manuf. 38(4) (1998) 329.

2. J . M. DULIEU-BARTON and M. C. FULTON, J. Strain 36(2) (2000) 81.

3. K. G. COOPER, "Rapid Prototyping Technology-Selection and Application" (Marcel Decker Inc., New York, 2001).

4. http://www.csa.com/hottopics/rapidman/overview.html

5. M. P . GROOVER, "Fundamentals of Modern Manufacturing Materials, Processes and Systems" (JohnWilley\&Sons Inc., NewYork, 2002) p. 772.

6. T. WHOLERS, Wohlers Report, Rapid Prototyping and Tooling. State of the Industry, Annual Worldwide Progress Report, 2001, Wohlers Associate Inc., USA.

7. M. MASERS and M. MATHY, Direct Manufacturing of

Custom-Made Hearing Instruments, an Implementation of Digital Mechanical Processing, SME RP and RM Conference, Cincinnati, April 2002.

8. R. HAGUE, Stereolithography Annual User Group (SLUG), Costa Mesa, Feb 2002, Design for Rapid Manufacturing Presentation.

9. R. J . M. HAGUE, S. MANSOUR and N. SALEH, "Design Opportunities with Rapid Manufacturing," International Journal of Assembly Technology \& Management 23(4) (2003) 346.

10. EPSRC Grant, Reference GR/R13517/01, 2001, Design for Rapid Manufacturing, P. Dickens and R. Hague.

11. R. J . HAGUE, R. I . CAMPBELL and P . M. DICKENS, "Implications on Design of Rapid Manufacturing," In Proceedings of the Institution of Mechanical Engineers Part C: J. Mechan. Engin. Sci. 217(C1) (2003) 25, ISSN 0954.

12. Huntsman (formerly Vantico) company. www.huntsman.com

13. www.3dsystems.com

14. P . F . JACOBS, "Fundamentals of Stereolithography" (Society of Manufacturing Engineers, Dearborn, Michigan, USA, 1992).

15. $P$. REEVES, "Reducing the Surface Roughness Deviation of Stereolithography

Components," Ph.D. thesis, University of Nottingham, October 1998.

16. ISO 527-1 and 2, Plastics-Determination of Tensile Properties, 1996.

2463

17. ISO 178, Plastics-Determination of Flexural Properties, 1997.

18. ISO 180, Plastics-Determination of IZOD Impact Strength 2001.

19. Zwick/Roller Materials Testing. www.zwick.com 
20. R. HARRIS, "Controlling the Morphology of Parts Produced by Stereolithography Injection Moulds," PhD thesis, Loughborough University, 2002, Chapt. 6.

21. TA Instruments Co. www.tainst.com

22. R. HAGUE, The Use of Stereolithography Models as Thermally Expandable Patterns in the Investment Casting Process, PhD thesis, Nottingham University, UK, 1997.

23. J . COLTON and B. BLAIR, Rapid Prototyping Journal. 5(2) (1999) 72.

24. J . Y. H. FUH, Y. S . CHOO, L. LU, A. Y. C. NEE, Y. S. WONG, W. L. WANG, T. MIYAZAWA and S. H.

HO. J. Mater. Proc. Techn. 63(1-3) (1997) 887.

25. J . S . ULLETT, J . W. SCHULTZ and R. P . CHARTOFF, Rapid Prototyping Journal, 6(1) (2000) 8.

26. C. M. CHEAH, A. Y. C. NEE, J . Y. H. FUH, L. LU, Y. S . CHOO and T. MIYAZAWA, J. Mater. Proc. Techn. 67 (1997) 46.

27. S . BIGER, A. MOSHONOV and S . KENIG, Composites 20 (1989) 341.

28. W. D. CALLISTER, "Materials Science and Engineering-An Introduction," (John Wiley and Sons, 2000) Chapt. 16.

29. D. R. ASKELAMD, The Science and Engineering of Materials, 3rd ed., 1989 (PWS Publisinng, Boston, MA, USA, 1989). Chapt. 15.

30. D. KARALAKAS and D. RAPTI, Journal of Prototyping, 8(4) (2002) 243.

Received 26 December 2002 and accepted 8 December 2003 2464 